\section{Commentary: Results of total coronary artery occlusion on graft patency following coronary artery bypass graft surgery: More information is needed!}

\author{
Harold L. Lazar, MD
}

In their practice of coronary artery bypass graft (CABG) surgery, surgeons will encounter coronary arteries that are chronically occluded. Should these chronic total occluded (CTO) vessels be bypassed, and if so what conduits should be used? Previous studies suggest that bypassing CTO vessels results in reduced early graft patency, especially when saphenous vein grafts (SVGs) are used. ${ }^{1}$ Lin and colleagues $^{2}$ sought to determine the effects of CTO vessels on long-term graft patency following CABG. The study population consisted of 301 patients from a single center previously enrolled in the Coronary Artery Bypass Grafting Surgery Off- or On-pump Revascularisation (CORONARY) study. ${ }^{3}$ Computed tomography angiograms were performed in 206 patients $(68 \%)$ at a mean follow-up of 6.8 years. The Fitzgibbon grading system $(\mathrm{A}=$ excellent, unimpaired; $\mathrm{B}=$ a stenosis $>50 \%$; and $\mathrm{O}=$ complete occlusion) was used to assess graft patency. The overall rates of type B or $\mathrm{O}$ graft failure was higher in CTO grafts to non-left anterior descending territories $(25.6 \%$ vs $16.2 \% ; P=.001)$ and was significantly higher in SVGs $(23.4 \%$ vs $12.5 \% ; P=.001)$ in the right coronary artery territory. There was no significant difference in long-term death, myocardial infarction, or the need for repeat revascularization between a CABG performed in patients with and without CTO lesions. Do all CTO vessels have reduced graft patency, and if so

From the Division of Cardiac Surgery, Boston University School of Medicine, Boston, Mass.

Disclosures: The author reported no conflicts of interest.

The Journal policy requires editors and reviewers to disclose conflicts of interest and to decline handling or reviewing manuscripts for which they may have a conflict of interest. The editors and reviewers of this article have no conflicts of interest.

Received for publication April 14, 2020; revisions received April 14, 2020; accepted for publication April 15, 2020; available ahead of print April 23, 2020.

Address for reprints: Harold L. Lazar, MD, Division of Cardiac Surgery, Boston University School of Medicine, 80 E Concord St, Boston, MA 02118 (E-mail: harold.1. lazar@gmail.com).

J Thorac Cardiovasc Surg 2022;163:1358-9

$0022-5223 / \$ 36.00$

Copyright (c) 2020 by The American Association for Thoracic Surgery

https://doi.org/10.1016/j.jtcvs.2020.04.055

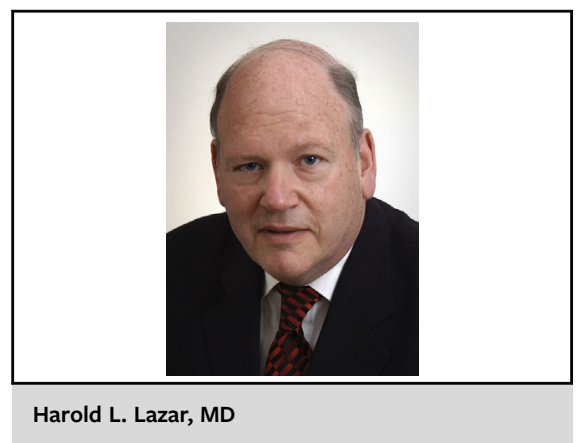

CENTRAL MESSAGE

Long-term patency of saphenous vein grafts is reduced in totally occluded coronary arteries, but more information is needed to determine the mechanism.

what is the mechanism for this graft failure? Unfortunately, there are several issues with this study that limit the conclusions that can be made.

The study population was small and was derived from a post hoc analysis from a single center looking at outcomes following on-pump versus off-pump CABG in which offpump CABG was associated with decreased graft patency. ${ }^{4}$ In the current study by Lin and colleagues, ${ }^{2}$ more patients in the CTO vessel group underwent off-pump CABG $(56 \%$ vs $48 \%$ ), but because of the small sample size this did not reach statistical significance. A repeat Computed tomography angiogram was obtained in only $68 \%$ of patients. A significant limitation was the lack of adherence to guidelinedirected medical therapy (GDMT) in these patients. At the time of discharge, only $20 \%$ of patients received a statin and $8 \%$ were taking an angiotensin-converting enzyme inhibitor. During follow-up, $68 \%$ of patients received a statin and $4 \%$ an angiotensin-converting enzyme inhibitor. No information is reported regarding low-density lipoprotein cholesterol levels of these patients. Lack of adherence to GDMT has been shown to influence long-term outcomes following CABG, especially vein graft patency. ${ }^{5}$ The decreased vein graft patency seen in these patients could also be explained by the poor adherence to GDMT, especially statins. We are not told what arterial grafts were used to bypass non-left anterior descending vesselspedicle or free right internal thoracic artery grafts, radial arteries, or right gastroepiploic vessels—and whether the 
anastomoses were performed in the right coronary artery or posterior descending artery.

To understand why graft patency is decreased in CTO vessels, 2 other factors must be taken into consideration: segmental wall motion and collateral flow. The lack of information on segmental wall motion in the area of myocardium supplied by the CTO vessel is another important limitation in the study by Lin and colleagues. ${ }^{2}$ Akinetic, dyskinetic, and severely hypokinetic segments of myocardium have been associated with decreased graft patency regardless of the type of conduit that is used. ${ }^{1}$ Another important factor is the degree of collateral flow in CTO vessels. Rentrop and colleagues ${ }^{6}$ developed a scale to quantify the extent of collateral filling in CTO vessels ranging from minimal filling of collateral channels, to partial filling, to complete filling of the vessel distal to the occulsion. Although early graft patency has not been associated with the Rentrop scale for collateral flow, the long-term effects of collateral flow on graft patency for arterial versus SVGs is unknown. ${ }^{1}$ Although there is concern that competitive flow in CTO vessels will decrease graft patency-especially SVGs-it is conceivable that an SVG to a CTO vessel with well-developed collaterals might have a higher patency if these collaterals supply blood to other vascular beds that serve viable but ischemic myocardium. Bypassing a CTO vessel in which the distal target has poor collateral blood flow, is small in caliber, is diffusely diseased, and supplies nonviable myocardium is unlikely to remain patent regardless of the type of conduit that is used.

Unfortunately, data from the study by Lin and colleagues $^{2}$ are insufficient to tell us what conduits should be used to bypass an occulsion in vessels with good collateral flow serving viable myocardium. Lin and colleagues ${ }^{2}$ should be encouraged to review their database to determine the effect of collateral flow and segmental wall motion in areas of myocardium serving CTO vessels. Until then, to determine the influence of a CTO vessel on graft patency following $\mathrm{CABG}$, more information is needed!

\section{References}

1. Oshima H, Tokuda Y, Araki Y, Ishi H, Murohara T, Ozaki Y, et al. Predictors of early graft failure after coronary artery bypass graft for chronic total occlusion. Interact Cardiovasc Thorac Surg. 2016;23:142-9.

2. Lin S, Rao C, Yang L, Yang X, Feng W, Sun H, et al. Impact of coronary total occlusion on graft failure and outcomes of coronary artery bypass grafting. J Thorac Cardiovasc Surg. 2022;163:1349-57.e5.

3. Lamy A, Devereaux PJ, Prabhakaran D, Hu S, Piegas LS, Shaka Z, et al. Rationale and design of coronary artery bypass grafting off or on pump. Am Heart J. 2012; 163:1-6.

4. Hattler B, Messenger JC, Shroyer AL, Collins JF, Haugen SJ, Garcia JA, et al. Of pump coronary artery bypass surgery is associated with worse arterial and saphenous vein graft patency and less effective revascularization: results from the veterans randomized on/off bypass (ROOBY) trial. Circulation. 2012;125:2827-35.

5. Pinho-Gomes AC, Azevedo L, Aha J-M, Park S-J, Hamza TH, Farkousch ME Compliance with guideline directed medical therapy in contemporary coronary revascularization trials. J Am Coll Cardiol. 2018;71:591-602.

6. Rentrop KP, Cohen M, Blanke H, Philips R. Changes in collateral filling immediately following controlled coronary artery occlusion by an angioplasty balloon in man. J Am Coll Cardiol. 1985;5:587-92. 